\title{
Análise eyetracking do uso da fotografia na divulgação científica
}

\author{
Janinne Barcelos \\ Doutoranda; Universidade de Brasília, Brasília, DF, Brasil; \\ janbarcelos@hotmail.com \\ Suely Gomes \\ Doutora; Universidade Federal de Goiás, Goiânia, GO, Brasil; \\ suelyhenriquegomes@gmail.com \\ Frederico Oliveira \\ Mestre; Universidade Federal de Goiás, Goiânia, GO, Brasil; \\ freddroliveira@gmail.com
}

Resumo: Este trabalho tem como objetivo verificar o uso de imagens técnicas para a compreensão de textos com conteúdo científico na divulgação da ciência. Parte-se da hipótese de que, associado à fotografia, o texto científico tem maior possibilidade de despertar o interesse do leitor e facilitar o entendimento da informação. Apoia-se na teoria de Flusser, que defende que as imagens como a fotografia fornecem pensamentos menos abstratos do que os textos; nas pesquisas de Samain, que classificam a fotografia como valioso meio de comunicação; e os esforços de outros estudiosos como Correia, Gruszynski e Castedo, Machado e Mora - que acreditam que a fala e a escrita não mais precisam ser as únicas formas de comunicação científica. A pesquisa caracteriza-se como exploratória, com design experimental-laboratorial e adota abordagem mista (qualitativa e quantitativa). Ao serem apresentados a diferentes estruturas de texto científico (texto com fotografia, somente texto e somente fotografia), os resultados mostram diferentes padrões de leitura, grau de atenção e compreensão do texto científico. O texto com imagem foi melhor compreendido e considerado de fácil leitura, seguido do texto sem imagem. $\mathrm{O}$ material menos compreendido foi aquele que apresentou somente a imagem. Os participantes que receberam textos consideraram que a fotografia auxilia na leitura e apreensão do conteúdo. O grupo que recebeu só imagem sentiu falta do texto. Considera-se que a hipótese da pesquisa foi confirmada.

Palavras chave: Popularização da ciência. Eye tracker. Fotografia. 


\section{Introdução}

Nos últimos dois séculos, o conhecimento científico tornou-se um dos elementos centrais da cultura ocidental. Desde a resolução adotada pela Organização das Nações Unidas (ONU), na década de 40, "toda pessoa tem o direito [...] de participar no progresso científico e nos benefícios que deste resultam" (ORGANIZAÇÃO DAS NAÇÕES UNIDAS, 2009). Compreender as descobertas científicas, em especial, aquelas informações que afetam diretamente as nossas vidas, como as decisões políticas, as variações econômicas, as relações sociais, a saúde e tantas outras é um direito do cidadão na sociedade atual. Por outro lado, a ciência precisa do envolvimento da sociedade nas políticas de Ciência, Tecnologia e Informação (C\&TI) por uma questão de sobrevivência. A urgência na divulgação e democratização dos resultados alcançados pela ciência potencializa-se à medida que a sociedade passa a financiá-la e estes tornam-se essenciais para a promoção do desenvolvimento econômico e social de qualquer país. "Não deve a sociedade exigir resultados práticos dos esforços do seu próprio investimento?”, questionase Tundisi (1995, p. 8). Essa questão pressiona os cientistas e agências financiadoras da ciência para adotarem medidas para tornarem suas pesquisas de fácil compreensão para a população.

Por essas razões, problemas como a falta de interesse e o baixo nível de compreensão em assuntos ligados à ciência e tecnologia colocam-se como grandes desafios para políticos, governantes e a própria comunidade científica. Para viabilizar a ampla participação da sociedade nos rumos da ciência e tecnologia, torna-se mandatório promover, ao maior número possível de pessoas, o acesso às informações e propiciar as condições necessárias para compreensão do modo de produção do conhecimento científico. Nesse ímpeto, é necessário superar as barreiras na comunicação entre cientistas e público leigo, provocadas pela linguagem de difícil compreensão.

A estruturação do campo do jornalismo científico e a formação de profissionais jornalistas adequadamente capacitados para mediarem informações entre o especialista e o público leigo foram avanços significativos na solução da 
problemática aqui levantada. Observa-se que um número crescente de jornalistas científicos e de pesquisadores ${ }^{1}$ têm se dedicado à divulgação científica adotando uma linguagem mais coloquial, atraente, objetiva e simples (OLIVEIRA, 2002). Entretanto, cabe ressaltar que, mesmo reconhecendo os avanços nessa área, a interação entre jornalistas e cientistas igualmente esbarra em muitos desafios. Tem-se, de um lado, o despreparo dos profissionais de comunicação para manipular as informações científicas, apesar da ampliação de cursos de formação de jornalismo científico, a exemplo daqueles promovidos pelo Laboratório de Estudos Avançados em Jornalismo (LABJOR) da Universidade de Campinas (UNICAMP), o Núcleo José Reis da Universidade de São Paulo (USP). Por outro lado, identifica-se a dificuldade que os pesquisadores têm para adaptar a linguagem técnica, cheia de normas, padrões, estilo e terminologias próprias do mundo da ciência - em informações compreensíveis para os não especialistas.

Apesar da importância do jornalismo científico e sua aguerrida defesa em favor da divulgação de ciência e tecnologia (OLIVEIRA, 2002), indicadores mostram que a procura por atualização sobre o tema pela população leiga acontece ocasionalmente. Os resultados da pesquisa "Percepção Pública da Ciência e Tecnologia no Brasil", realizada pelo Ministério da Ciência, Tecnologia, Inovação e Comunicação (MCTIC), em 2015, revelam, por exemplo, que somente $12 \%$ da população com 16 anos ou mais visitavam algum museu ou centro de ciências anualmente - número muito pequeno comparado a alguns países europeus, onde a média de visitação chega a atingir 30\%. Ainda de acordo com a pesquisa, $85 \%$ da população brasileira sequer conhecem os cientistas e as instituições de pesquisa do país, e cerca de $40 \%$ dos entrevistados não se interessam por Ciência e Tecnologia (BRASIL. MINISTÉRIO DA CIÊNCIA, TECNOLOGIA, INOVAÇÃO E COMUNICAÇÃO, 2015).

Em estudo encomendado pelo Conselho Nacional de Desenvolvimento Científico e Tecnológico (CNPq) ao Instituto Gallup, em 1987, 70\% da população urbana brasileira tinham interesse em C\&T. Comparado com os dados de 2015, observa-se que menos brasileiros se interessam por essas 
questões. Esse dado contradiz a previsão de Oliveira, que esperava uma demanda crescente pela divulgação científica "já que os avanços da C\&T são cada vez mais determinantes no contexto social, econômico e político da vida humana" (OLIVEIRA, 2002, p.17). Claramente, isso não ocorreu. Os brasileiros não se interessam pela C\&T sob a alegação de não as compreender (MINISTÉRIO DA CIÊNCIA, TECNOLOGIA, INOVAÇÃO E COMUNICAÇÃO, 2015). A maioria dos brasileiros ainda considera a linguagem dos cientistas complicada e de difícil compreensão (FUJIYOSHI; COSTA, 2003).

Certamente, diante da realidade brasileira, faz-se necessário maior investimento das universidades na formação desses profissionais, através da implementação de disciplinas de divulgação científica e programas de pósgraduação, com ênfase nessa área. Como apontou Hernando (2005), pesquisadores deveriam assistir às aulas pertencentes ao campo da comunicação e jornalistas deveriam, minimamente, ter disciplinas de história e metodologia científicas em suas matrizes curriculares - como já fizeram alguns países da Europa e da América do Norte, consideravelmente mais bem-sucedidos que o Brasil, no envolvimento do público com a ciência.

Paralelamente, outras ações para a compreensão do conhecimento científico podem ser tomadas. Dentre as diversas possibilidades, destacamos aqui a apropriação de outras linguagens para a divulgação da ciência por reconhecer que a fala e a escrita não precisam ser as únicas formas de comunicação consideradas na construção do conhecimento científico. Para colaborar com o discurso dos cientistas e dos jornalistas científicos e diminuir o abismo entre comunidade científica e sociedade, propomos o uso da fotografia como linguagem capaz de retratar eventos, pessoas e objetos; de representar uma realidade; de comunicar e difundir novas ideias e que, ao mesmo tempo, se apresente como código comum entre pesquisadores, jornalistas e público leigo.

Nossa hipótese é de que, associado à imagem fotográfica, o texto científico tem maior possibilidade de despertar o interesse do público leigo e facilitar o entendimento da informação científica, sem, no entanto, com ele 
(texto) concorrer. A hipótese foi construída a partir das pesquisas de Samain (2012) que consideram a fotografia como valioso meio de comunicação, bem como na iniciativa do CNPq, Prêmio de Fotografia Ciência e Arte - que aponta para a importância da associação entre temas de pesquisas científicas e imagens fotográficas (BRASIL, 2015); e os esforços de outros estudiosos como Correia (2011), Gruszynski e Castedo (2008), Machado (2001) e Mora (2003), que declaram que a fala e a escrita não mais precisam ser as únicas formas de comunicação científica.

\section{A falsa dicotomia entre texto e imagem}

Em sua evolução, o homem passou da utilização de riscos rudimentares - com suas relações de significação circulares - para a utilização de arranjos imagéticos unidimensionais, nos quais o significado pudesse ser apresentado em linhas. Segundo Flusser (2002), a escrita, as escrituras e os textos surgiram da transcodificação das imagens em palavras; do tempo circular em linear; da tradução de cenas em processos. Por consequência, foi através de textos (verbais ou escritos) que a produção do conhecimento organizado se articulou ao longo dos anos, graças à extensa produção científica de periódicos, livros, congressos, seminários e revistas, entre outras formas de comunicar a ciência.

Da passagem da busca por significação nas imagens, para a busca por significação nos textos, surgiram consequências imprevistas. Para Flusser (2002), foi nesse momento que o homem se afastou do mundo concreto e aproximou-se mais da abstração, já que os textos não significam o mundo diretamente, mas o representam através de imagens, os conceitos não significam fenômenos, significam ideias. "Decifrar textos é descobrir as imagens significadas pelos conceitos. A função dos textos é de explicar as imagens, a dos conceitos é de analisar as cenas. Isto é, a escrita é um meta-código da imagem.” (FLUSSER, 2002, p. 10).

Samain (2015) se alia ao pensamento de Flusser ao argumentar que: 
[...] a escrita não reproduz a palavra, a escrita torna a palavra visiva. [Na verdade,] a escrita é uma dupla imagem. Ela é primeiro figura, desenhos, curvaturas. E depois ela remete a uma imagem. [Ou seja] na base de qualquer concepção de conhecimento estão as imagens.

Depreende-se do pensamento dos dois autores acima citados que o propósito das imagens é mediar o homem e o mundo, o propósito dos textos é associar e descrever as imagens e o mundo, através dos conceitos. Esse fluxo colocou a imagem e a palavra em contínua disputa por espaço no processo de produção do conhecimento e, por muitas vezes, deslocou a imagem a um espaço menos privilegiado que o texto. Esse deslocamento leva ao que Flusser denomina de textolatria: um tipo de alienação do homem em relação aos seus próprios instrumentos. Em vez de se servir do texto, o homem passou a servir ao texto. "Exemplo impressionante de textolatria é a 'fidelidade ao texto', tanto nas ideologias (cristã, marxista etc.) como nas ciências exatas." (FLUSSER, 2002, p. 11).

Exemplos da predileção ao texto são amplos. Em diversas áreas de pesquisa, como a Comunicação, vemos longas descrições de episódios de jornais e telenovelas, imagens fotográficas e outros elementos imagéticos, feitas por meio de textos lineares (GRUSZYNSKI; CASTEDO, 2008). Em muitos trabalhos, quando as imagens são utilizadas na documentação dos estudos, essas são apresentadas sem a menor preocupação técnica e estética na divulgação dos resultados. Muitas das fotografias, por exemplo, são tratadas com pouca importância, com simplicidade, sem relação direta com o assunto discutido no texto e com legendas ainda mais confusas (SILVA, 2012).

Como argumenta Rouillé (2009, p.16), "no plano das pesquisas, das teorias e dos textos [...] a fotografia continua amplamente inexplorada, ignorada ou abandonada por autores e teóricos, tendo seu interesse e complexidade geralmente subestimados." É quase como se negassem que as imagens fornecem informações que, muitas vezes, estão aquém ou além do texto. Quase como se esquecessem de que "[...] a imagem é uma forma de construção do pensamento tão sofisticada que sem ela provavelmente não teria sido possível $o$ desenvolvimento [das] ciências." (MACHADO, 2001, p. 23). 
Ao valer-nos deste argumento, não estamos iniciando aqui uma tentativa de estabelecer qualquer relação hierárquica entre texto e imagem. Estamos, na verdade, discordando da falsa dicotomia que preestabelece o texto como elemento mais relevante na construção do conhecimento ou como elemento autocontido e autossuficiente na formação de sentidos. Também, atentos ao alerta dado por Flusser (2002), não estamos apontando para o movimento contrário: a idolatria, um estado alucinatório em que servimos às imagens. Mesmo porque não acreditamos que publicações com o uso exclusivo de imagens possam, de qualquer forma, facilitar o entendimento da ciência. Nossa defesa é em favor de uma reflexão sobre a função do texto e da fotografia na compreensão da ciência em uma relação simbiótica.

Certamente, assim como textos podem ser lidos apenas a partir de conhecimento prévio do código linguístico, imagens também necessitam de referências para serem interpretadas e compreendidas. Para Manguel (2001), é justamente por causa dessa propriedade de referência que podemos dizer que uma imagem é um texto a ser lido e que o leitor constrói sua "[...] narrativa por meio de ecos de outras narrativas, por meio da ilusão do auto-reflexo, por meio do conhecimento técnico e histórico, por meio da fofoca, dos devaneios [...]" (MANGUEL, 2001, p. 28). É nessa mesma perspectiva que Aumont (1993, p. 86, grifo do autor) afirma que o leitor é um “[...] parceiro ativo da imagem emocional e cognitivamente.”.

De maneira semelhante, assim como produções textuais sofrem influências de seu 'narrador', a elaboração de um registro imagético (reproduções de cenas em pinturas, desenhos ou fotografias, por exemplo) também traz elementos subjetivos de seu produtor. Porém, se por um lado as imagens são complexas e não se dão em uma definição única porque falam em todas as direções, por outro, “essas são um meio de comunicação riquíssimo, [com] uma capacidade de despertar fantástica." (SAMAIN, 2015, doc. não paginado), podendo, na construção de sentidos, encontrar no texto as complementariedades de que também precisam. O autor argumenta ainda que “[...] a imagem é capaz de ideações - capaz de suscitar ideias [...] Todavia, a 
elas negamos essa habilidade, sem, no entanto, nos aprofundarmos das razões." (SAMAIN, 2012, p. 35).

A imagem, quando associada ao texto, tem seu potencial de ideação limitado, uma vez que este instaura um modo de olhar e interpretar aquela. É nesse sentido que se afirma que texto e imagem não se excluem e podem ser complementares. Desenvolvem papéis próprios no processo de produção do conhecimento e, quando juntos, produzem outro sentido que não pode ser apreendido separadamente: só palavra ou só imagem. Essa é a razão pela qual acreditamos que a inter-relação de ambos pode construir um caminho privilegiado na busca pelo entendimento da ciência e consequente formação do conhecimento. Imagens criam textos, que, por sua vez, criam imagens. É um movimento cíclico, mas, sobretudo, complementar.

Contudo, ao propor um maior investimento na produção de imagens que possam ser utilizadas na divulgação de estudos científicos, não tratamos do uso indiscriminado de qualquer imagem, resultado do ímpeto ou da expressão pura de seu produtor. Propomos o uso de imagens capazes de representar as ciências - o que "[...] implica um estudo, uma pesquisa em que essa ação adote a linguagem estruturante, hierárquica e sequencial do método científico, mas adornando-a com o sabor e o saber da Estética." (CORREIA, 2011, p. 226).

Também não advogamos em nome das imagens que são pura expressão da arte. Apontamos para o uso da imagem objeto, mídia, para essa plataforma onde o traço da cultura e do real empírico são expressos e impressos. Imagens que são representações de uma materialidade empírica e que, ao mesmo tempo, permitam um processo de produção menos demorado que os desenhos, as gravuras e as pinturas. Sumariamente, as fotografias.

\section{A fotografia como o registro do real empírico}

Simbiótica, desde a invenção da câmera escura, a relação entre ciência e fotografia já testemunhou diversas fases. Como ferramenta da pesquisa científica, a fotografia garantiu grande contribuição para o desenvolvimento de ciências da natureza e do homem, cumprindo as funções de arquivar, ordenar, 
fragmentar e unificar o real; de modernizar os saberes sobre a natureza e os corpos, registrando sem esquecimento; e de informar o público, através da forte aliança com a tipografia e a mídia (ROUILLÉ, 2009). Charles Darwin, por exemplo, ciente de que poderia imprimir a cena em papel fotográfico e apreender detalhes despercebidos a olho nu, utilizou fotografias para desenvolver suas concepções evolutivas e estudar a expressão das emoções no homem e nos animais. Na astronomia, o advento da fotografia tornou possível esmiuçar temas complexos como o Big Bang, a matéria negra e os planetas extrassolares (SCHILLING; CHRISTENSEN, 2009). Na antropologia, a evocação da memória serviu como meio de conhecimento da cultura humana, através de fotografias tiradas em expedições científicas que registravam desde os monumentos das civilizações antigas ao cotidiano dos povos (FABRIS; KERN, 2006). No entanto, a veracidade documental da fotografia - alcançada por seu caráter maquínico e expurgação da subjetividade (como se pensava na época) - foi contestada a partir de 1980.

Como objeto da pesquisa científica, a imagem fotográfica foi elevada para o plano da reflexão conceitual e passou a fazer parte das discussões que pensavam a sociedade e a cultura do mundo pós-guerra. Para Flusser (2002), o que vemos ao contemplar uma fotografia “[...] não é 'o mundo', mas determinados conceitos relativos ao mundo [...]" (FLUSSER, 2002, p. 15, grifo do autor). Ou seja, tanto quanto outras imagens visuais, a imagem fotográfica é uma representação do real visível. Portanto, é uma linguagem que será percebida e compreendida pelo espectador através de suas referências e atos perceptivos e psíquicos (AUMONT, 1993). Sendo assim, como poderia a fotografia ser uma imagem representativa das ciências? Em outras palavras, como a fotografia poderia garantir a transmissão e a apropriação da informação científica nela contida?

O choque barthesiano diante da fotografia traz, como resposta às questões acimas colocadas, a ideia de mimese da realidade (BARTHES, 2014). Dubois (2009), no entanto, considera essa perspectiva de Barthes (1990) - a fotografia como espelho do real, seu analagon perfeito - um tanto quanto 
ingênua. Sem negar o fato da relação da fotografia com o real concreto, Dubois procura recolocar, “[...] positivamente, mas de outra forma, a questão da pregnância do real na fotografia.” (DUBOIS, 2009, p. 45). Assim, o autor considera que, antes de ser mimese, a fotografia é um traço do real. Nesse sentido, a fotografia é “[...] em primeiro lugar índice. Só depois ela pode tornarse parecida (ícone) e adquirir sentido (símbolo).” (DUBOIS, 2009, p. 53).

A fotografia índice (rastro do real) está submetida a quatro princípios: o da conexão física entre imagem e referente; da singularidade que nos remete a um único referente empiricamente determinado; de designação que aponta para um objeto definido e; finalmente, do atestado que testemunha a existência de uma realidade. O conjunto destes princípios, associado às condições de enunciação, determina o significado da fotografia. Desta forma, esta retrata um momento específico do objeto que representa e sua significação é construída na “dimensão pragmática” (DUBOIS, 2009).

Evidentemente, os programas de edição de imagens podem comprometer esta relação e o sentido atribuído às fotografias, ao romper os princípios supracitados. Sabemos que, mesmo no tempo da fotografia analógica, a manipulação de fotos já era feita por mestres especializados em criar ilusões. Atualmente, a manipulação dessas imagens por computador pode ser feita até por leigos, tamanha a facilidade em operar suas ferramentas de edição, cada vez mais intuitivas e acessíveis. Contudo, falamos aqui de originais que mantenham vínculo singular com o objeto representado, sejam capazes de designá-lo e atestam sua existência (DUBOIS, 2009).

Diante do exposto, não há como negar que a fotografia original é sempre uma imagem de algo real, testemunha de uma existência. Justamente essa característica confere a esta categoria de imagem a capacidade de representar as ciências, de demostrar visualmente o que de outra maneira não poderia ser visto. Entretanto, ressaltamos que o significado da imagem fotográfica é construído em sua relação com o objeto e as condições em que ela é enunciada, ou seja, a fotografia "[...] nada nos diz sobre o sentido dessa representação; ela não nos diz 'isto quer dizer aquilo'.” (DUBOIS, 2009, p. 52). 
Assim, não são todas as fotografias que podem representar adequadamente as ciências. É necessário, então, que se discuta teórica e metodologicamente a produção destas imagens.

\section{As fotografias representativas das ciências}

O aprimoramento das técnicas de fotografar encontrou muitas formas para documentar, tanto o homem quanto a natureza, dando novas possibilidades para a tentativa de registrar objetos minúsculos, muito distantes, muito breves ou difíceis de serem captados pelo olho humano. Entre alguns exemplos, podemos citar a fotomicrografia - que se utiliza de câmeras acopladas a microscópios, possibilitando fotografar desde componentes químicos até plantas, animais e bactérias; a termofotografia - que captura imagens de objetos em todas as temperaturas; a fotografia de alta velocidade - usada pelos cientistas para estudar o movimento físico, medindo fenômenos como tensão da superfície e efeitos gravitacionais.

Há ainda outras técnicas como a macrofotografia, fotografia infravermelha, fotografia de fluorescência, fotografia morfométrica, subaquática e ultravioleta. O ato de fotografar, tão somente, mesmo aliado ao uso de tecnologias avançadas, não garante que uma imagem seja a representação de qualquer ciência. Uma imagem que represente as ciências deve atentar para três premissas fundamentais e simultâneas: reunir, em si mesma, a informação de forma fácil, perceptiva e assimilável em termos cognitivos; veicular, por si só, a mensagem científica nela contida a outros indivíduos que a desconhecem; e criar a empatia emotiva necessária para fomentar a apreciação deste registro imagético e consequente apreensão do conhecimento nela encapsulado (CORREIA, 2011).

Essa proposição pode ser testada, inicialmente, a partir do Prêmio de Fotografia - Ciência \& Arte, criado pelo CNPq, em 2011. O projeto aponta para a necessidade "[...] de associar as tecnologias [...] à produção de imagens com temas sobre pesquisa científica, tanto quanto objeto como produto de estudos e análises fundamentados na ciência." (BRASIL, 2015, doc. não paginado). A 
partir dos critérios de julgamento que regulam o Prêmio, o $\mathrm{CNPq}$ somente laureia fotografias com impacto visual, inovação, relevância da imagem para a pesquisa, contribuição para a popularização e divulgação científica e tecnológica, e qualidade estética.

Ou seja, para ser considerada uma imagem capaz de "contribuir com a divulgação e a popularização da ciência e tecnologia" a fotografia deve ter:

a) a capacidade de afetar e surpreender o espectador;

b) o potencial para criar novas perspectivas de uso na pesquisa científica;

c) o potencial para aproximar o público da ciência e tecnologia;

d) e critérios técnicos - composição, profundidade de campo, luz e sombra, granulação da imagem, perspectiva, entre outros.

\section{Metodologia e diário da pesquisa}

A hipótese levantada na presente pesquisa é que, associado à fotografia, o texto científico tem maior possibilidade de despertar o interesse do público leigo e facilitar o entendimento da informação nele contida. Para testar empiricamente esta hipótese, adotamos como abordagem quantitativa e qualitativa um conjunto de tecnologias de rastreamento ocular, mais conhecido como eye tracker.

O eye tracker (Figura 1) permite, em ambiente real ou controlado, medir e registrar os movimentos oculares do pesquisado, tornando possível determinar áreas de fixação, tempo (grau de atenção), ordem (padrão de leitura) e número de vezes que o olhar retorna a um determinado ponto durante estímulo visual. Em estudos desta natureza, pressupõe-se que a gravação dos movimentos oculares aponta, em um traçado dinâmico, onde está dirigida a atenção do indivíduo num determinado campo visual (BARRETO, 2012). A partir do traçado, o aparelho produz métricas que viabilizam os registros de reações, padrões de leitura e de comportamento frente a diferentes estímulos visuais. 


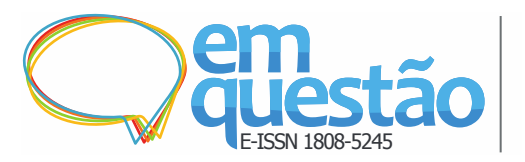

Análise eyetracking do uso da fotografia na divulgação científica

Janinne Barcelos, Suely Gomes e Frederico Oliveira

Figura 1 - Eye tracker: tecnologias de rastreamento do olhar

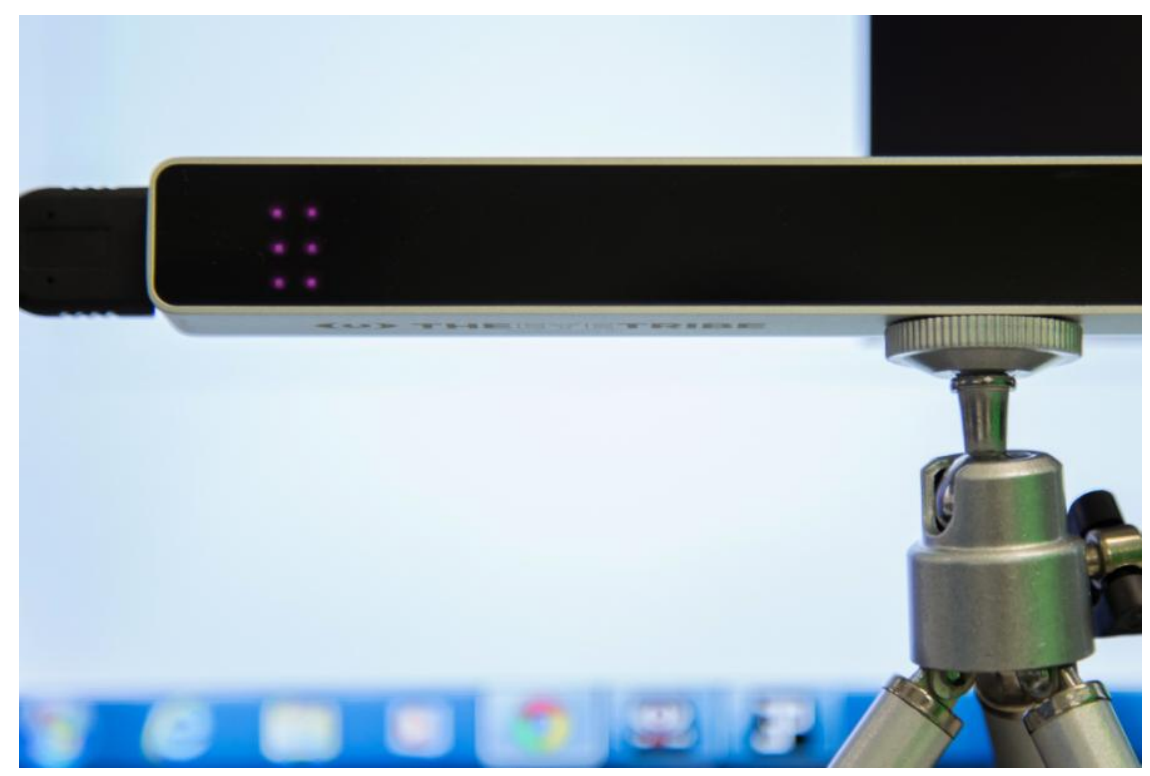

Fonte: Dados da pesquisa.

Ao todo, foram utilizados quatro eye trackers, com precisão de 0,5 a 1 grau e faixa de trabalho de 45 a 75 centímetros. Entre as tecnologias disponíveis no mercado, o equipamento de valor mais acessível foi encontrado na Dinamarca (norte da Europa) e comprado pelo site da empresa. Além dos aparelhos de rastreamento ocular, foram imprescindíveis, ainda: quatro computadores Compaq Elite 8300 SFF, com processador Intel Core i5- 4670, 3.4 GHz, 8 GB de memória RAM, sistema operacional Windows 7 Professional e conexões USB 3.0; quatro monitores LED modelo E2001P-BN (V206HZ, com resolução máxima: 1600 x 900 pixels, tamanho da tela: 20 polegadas, e ângulo de inclinação e rotação $-5^{\circ} \mathrm{a}+15^{\circ}$ ); internet disponível durante todos os testes.

\subsection{O laboratório}

O laboratório para a coleta de dados foi montado numa das salas da UFG. Durante o processo de montagem, que durou uma semana, foi necessário eliminar estímulos visuais como quadros, avisos e objetos considerados desnecessários para a pesquisa. As paredes de vidro foram isoladas com papel 
para evitar a distração dos envolvidos com o fluxo de trabalhadores e visitantes do órgão.

Além disso, as cadeiras giratórias foram deliberadamente substituídas por cadeiras fixas para controlar a mobilidade dos pesquisados, já que o raio infravermelho emitido pelo eye tracker opera dentro de uma limitação espacial. As telas dos computadores foram colocadas na vertical, para evitar a rolagem do ecrã, de modo que cada página do conteúdo pudesse ser visualizada por completo (Figura 2); e o espaço foi organizado para evitar que os participantes conversassem entre si.

Figura 2 - Configuração do laboratório para a aferição das atividades de leitura

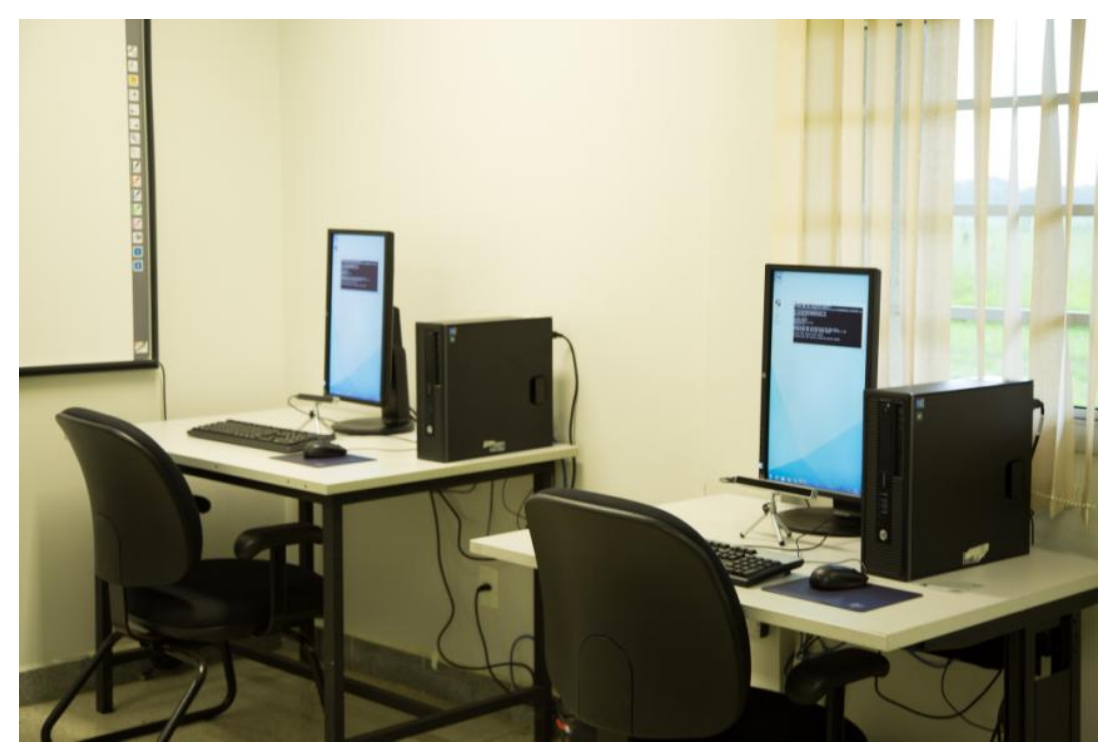

Fonte: Dados da pesquisa.

\subsection{Textos e imagens}

A seleção do conteúdo a ser interpretado pelo grupo pesquisado, ou seja, os textos e as imagens que serviram de base para a aferição com os eye trackers, foi realizada após ampla investigação sobre os canais brasileiros de divulgação científica impressos e virtuais. A partir desse rastreamento inicial, optamos pela reportagem intitulada "Existência luminosa", que trata da capacidade de seres vivos de emitir luz (ou seja, bioluminescência), disponível na revista National Geographic Brasil (NatGeo), edição 180, de março de 2015. 
Tal decisão baseou-se nos seguintes fatos: a NatGeo tem foco em uma área específica. Essa característica torna mais fácil isolar variáveis como a área de formação dos pesquisados; dentre as revistas nacionais de Divulgação Científica, a NatGeo é a que mais investe na produção de fotografias em suas reportagens. Logo, teríamos acesso às fotografias que correspondessem aos critérios apontados pelo CNPq; a reportagem "Existência luminosa" faz parte da edição mais recente no período do experimento e sua extensão (menos de 5 páginas) favorece a leitura sem fadigar os participantes.

\subsection{Os participantes da pesquisa}

O convite para participação no corpus da pesquisa foi feito exclusivamente aos alunos de graduação da Universidade Federal de Goiás (UFG). Os critérios usados para a inclusão no grupo de coleta foram:

a) alunos pertencentes às diferentes áreas do conhecimento;

b) com idade a partir de 18 anos;

c) vinculados à UFG;

d) que concordaram voluntariamente em participar do estudo.

Em três dias de recrutamento, 35 graduandos aceitaram participar das atividades propostas pelo estudo (a serem detalhadas mais adiante). Do total de 35, 29 voluntários compareceram no laboratório, sendo que três deles não conseguiram passar pelo procedimento de calibragem do eye tracker, e outros dois tiveram os dados desprezados: um por pertencer à mesma área de estudo de que trata a reportagem e o outro por estar na segunda graduação.

Finalmente, nosso corpus foi composto por 24 graduandos voluntários que moram na Região Metropolitana de Goiânia, com idade de 18 a 30 anos. Entre eles, há quem cursa: Administração (1), Biblioteconomia (1), Ciências Econômicas (1), Ciências Sociais (1), Design Gráfico (4), Engenharia Agronômica (1), Engenharia da Computação (2), Engenharia Física (2), Gestão 
da Informação (2), História (3), Matemática (1), Música (1), Musicoterapia (1), Relações Internacionais (1) e Relações Públicas (2).

Para permitir a comparação do nível de compreensão dos graduandos gerado, primeiramente, por exposição exclusiva ao texto; em seguida, por exposição à reportagem completa (texto e fotografias); e, finalmente, por exposição apenas das fotografias, o corpus de 24 voluntários foi dividido, por sorteio, em três grupos de oito participantes cada, os quais chamamos de Grupo I, Grupo II e Grupo III.

Importa salientar que o processo de recrutamento e quantidade de participantes incluídos em cada grupo nesta pesquisa seguiu as recomendações de Pernice e Nielsen (2009). Com base em análises de usabilidade e estimativas de margem de erro, os autores entendem que "Em um estudo qualitativo de rastreamento ocular, cerca de seis usuários são tipicamente suficientes para a avaliação [...]” (PERNICE; NIELSEN, 2009, p. 20, tradução nossa).

\subsection{Limitações do rastreamento ocular}

O uso das tecnologias de rastreamento ocular oferece condições suficientes para determinar, quantitativamente, onde está fixado o olhar do participante no momento da aferição, e que percursos faz seu olhar durante o exame de um determinado conteúdo. No entanto, não foi possível o uso exclusivo dessa abordagem para verificar a compreensão dos participantes sobre a reportagem "Existência luminosa".

Isso por que, muito embora o eye tracker seja capaz de aferir o comportamento do olhar, suas métricas não o explicam, não revelam a atividade cognitiva do participante quando fixa os olhos na tela do computador, se ele está a contemplar o conteúdo ou a reparar um inseto que pousou sobre o ecrã, por exemplo. Portanto, para colaborar com a compreensão qualitativa do fenômeno, foi necessária a aplicação de questionários com questões abertas e fechadas. Para facilitar o manuseio das informações, no que diz respeito à compilação dos dados e também ao seu armazenamento, os questionários foram elaborados no 
Google Docs e apresentados aos participantes logo após a coleta das métricas com os eye trackers.

\subsection{Coleta de dados}

As atividades de coleta de dados tiveram duas horas e meia de duração e foram moderadas pela pesquisadora responsável, com auxílio de pesquisadores colaboradores. A aplicação das atividades em cada grupo se deu da seguinte maneira: Grupo I: os participantes fizeram a leitura (somente) do texto da reportagem "Existência luminosa" e a partir de suas percepções responderam ao questionário; Grupo II: os integrantes leram a reportagem completa (texto e fotografias), para então responder ao questionário; Grupo III: os voluntários visualizaram (exclusivamente) as fotografias da referida reportagem e, também, responderam ao questionário de interpretação.

\section{Resultados}

O questionário procurou identificar se os participantes, mediante o material recebido, compreenderam o conteúdo; conseguiram identificar o tema; extraíram as ideias periféricas do conteúdo; conseguiriam explicar o conteúdo aos colegas; acreditam que o uso de fotografias auxiliaria ou auxiliou no entendimento do texto, ou, no caso do grupo II, se o uso de textos auxiliaria na compreensão das fotografias.

Os resultados (Tabela 1) apontaram que no Grupo I, apenas quatro (50\%) estudantes disseram entender o texto. Por outro lado, quando apresentados ao texto e às fotografias, os oito participantes do Grupo II (100\%) disseram compreender a reportagem. A dificuldade na formação de sentido se repetiu no Grupo III. Nenhum dos pesquisados conseguiu responder corretamente qual era o tema da leitura - o mais próximo que se chegou foi a identificação da área da ciência que tratava a reportagem (Ciências Biológicas). Esse dado nos remete às proposições de Dubois (2009), quando o autor afirma que a fotografia não tem um sentido em si mesma. 


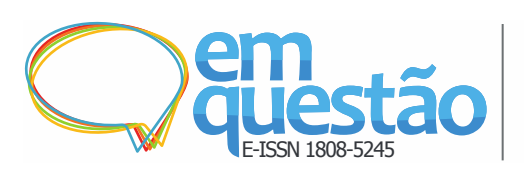

Análise eyetracking do uso da fotografia na divulgação científica

Janinne Barcelos, Suely Gomes e Frederico Oliveira

Tabela 1 - Apreensão do conteúdo do material (textos e imagem)

\begin{tabular}{|c|c|c|c|c|c|c|}
\hline Atividade & $\begin{array}{c}\text { Grupo I } \\
\text { (F) }\end{array}$ & $\%$ & $\begin{array}{l}\text { Grupo II } \\
\text { (F) }\end{array}$ & $\%$ & $\begin{array}{l}\text { Grupo III } \\
\text { (F) }\end{array}$ & $\%$ \\
\hline Declararam compreender o conteúdo & 4 & $50 \%$ & 8 & $100 \%$ & 6 & $75 \%$ \\
\hline Identificaram o tema & 7 & $87,5 \%$ & 8 & $100 \%$ & 0 & $0 \%$ \\
\hline $\begin{array}{l}\text { Extraíram ideias periféricas do } \\
\text { conteúdo }\end{array}$ & 2 & $25 \%$ & 7 & $87,5 \%$ & 0 & $0 \%$ \\
\hline $\begin{array}{l}\text { Consideraram o conteúdo de fácil } \\
\text { compreensão }\end{array}$ & 5 & $62,5 \%$ & 7 & $87,5 \%$ & 6 & $75 \%$ \\
\hline $\begin{array}{l}\text { Declararam capacidade de explicar o } \\
\text { conteúdo aos colegas }\end{array}$ & 1 & $12,5 \%$ & 5 & $62,5 \%$ & 2 & $25 \%$ \\
\hline $\begin{array}{l}\text { Afirmaram que a relação } \\
\text { texto/imagem facilita a compreensão } \\
\text { do conteúdo }\end{array}$ & 7 & $87,5 \%$ & 6 & $75 \%$ & 8 & $100 \%$ \\
\hline
\end{tabular}

Fonte: Dados da pesquisa.

Ao compararmos as respostas dos três grupos, sobre o tema exibido, também é possível notar diferenças: oito participantes do Grupo II (100\%) souberam dizer o tema central da reportagem e sete $(87,5 \%)$ conseguiram extrair as ideias periféricas presentes ao longo da reportagem. Neste grupo, sete participantes $(87,5 \%)$ consideraram que o conteúdo era de fácil compreensão, e cinco $(62,5 \%)$ disseram que conseguiriam explicar a reportagem para outra pessoa de modo que seu interlocutor entenda.

Já no Grupo I, os percentuais foram: sete participantes $(87,5 \%)$ souberam responder qual é o tema do texto; mas somente dois (25\%) foram capazes de extrair as ideias periféricas do texto - como, por exemplo, o habitat dos seres bioluminescentes e as razões de terem tal característica. Cabe destacar que cinco $(62,5 \%)$ estudantes deste grupo disseram considerar o texto 'fácil', enquanto quatro (50\%) não tinham certeza se o material havia sido compreendido. Demonstrando dificuldades para manipular informações extraídas da revista, 
sete $(87,5 \%)$ afirmaram não ter certeza se conseguiriam explicar o texto para outra pessoa.

Para o grupo III tem-se: nenhum participante respondeu qual o tema central da fotografia, mas, apesar dessa dificuldade de entender do que se tratava o material, seis $(75 \%)$ consideraram o conteúdo de fácil compreensão.

Ainda segundo dados coletados pelos questionários, sete participantes do Grupo II (87,5\%) atribuíram a compreensão da reportagem ao uso das fotografias. Do total, seis participantes (75\%) disseram que as imagens auxiliaram na interpretação e trouxeram elementos que o texto escrito não apresentava. No Grupo I, sete dos pesquisados $(87,5 \%)$ admitiram que o uso de fotografias poderia ajudar no entendimento daquilo que está escrito.

Por sua vez, o Grupo III - que visualizou apenas as fotografias da reportagem "Existência luminosa" - admitiu sentir falta do texto escrito para a compreensão daquilo que viram. Para todos os participantes, as imagens demandam a interlocução com textos para terem seu código linguístico compreendido. Esse resultado mostra que a fotografia científica, por si só, não consegue traduzir o seu conteúdo. Já o texto sem imagem, apesar de ter sua compreensão dificultada, não inviabilizou a apreensão do conteúdo.

Sobre a análise do comportamento ocular dos participantes do Grupo II, notamos que mais de $90 \%$ do grupo voltou a olhar as imagens depois de iniciar a leitura da reportagem. A Figura 3 mostra o percurso do olhar de um pesquisado do Grupo II durante a leitura da reportagem. Cada círculo azul corresponde a uma pausa do olhar e os números dentro dos círculos obedecem a ordem dessas pausas durante a leitura.

Notamos também, que $75 \%$ deles repetiram esse processo por, pelo menos, duas vezes. Se relacionarmos as respostas dos questionários com os mapas de percurso do Grupo II, torna-se admissível sugerir que esse movimento - ora interpretando o texto, ora interpretando imagens - corresponde ao esforço do participante para formar sentido daquilo que lê. 
Figura 3 - Percurso do olhar de participante do Grupo II

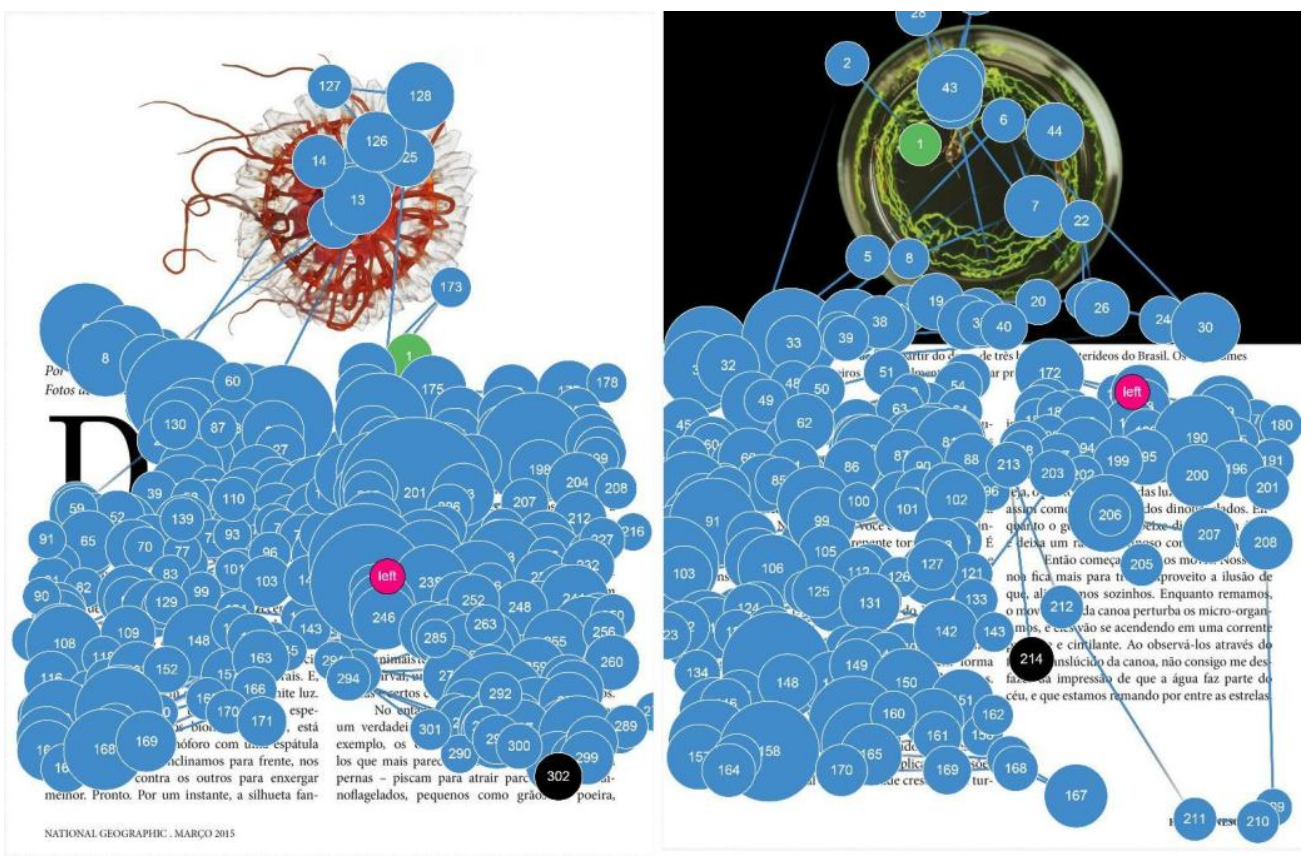

Fonte: Dados da pesquisa, a partir de dados coletados com o eye tracker.

Os aparelhos de rastreamento ocular também contaram os pontos de fixação de cada participante. Esta métrica está intimamente relacionada com a duração do olhar ao longo do exame de um determinado conteúdo. O número de fixações num elemento específico da tela do computador pode indicar a relevância desse elemento, ou seja, os elementos mais importantes serão fixados mais vezes.

Aqueles que leram o texto (Grupos I e II) têm, em média, 1.775 e 1.650 pontos de fixação. A pequena diferença entre a quantidade de pontos de fixação nos dois grupos (125 pontos) pode indicar que as fotografias expostas (para o Grupo II) não concorrem com o texto. Ou, até mesmo, que as informações geradas por elas não substituem aquelas originadas pelas palavras do texto. Afinal, com ou sem imagens, os dois grupos dispensaram médias similares de atenção nos escritos.

O mesmo acontece quando confrontamos os pontos de fixação nas imagens vistas pelos Grupos II e III: a contagem atinge 63 e 66 pontos, respectivamente. O que também faz pensar que a leitura do texto (pelo Grupo II) 
não interferiu na atenção dispensada para as imagens. Quem viu apenas imagem e quem leu a reportagem tem média de pontos de fixação muito semelhantes.

Nos mapas de calor, "[...] as áreas "quentes" ou de maior intensidade sinalizam os locais onde os usuários fixaram a sua atenção com maior frequência, ou seja, [...] onde se gerou maior volume de fixações visuais." (BARRETO, 2012, p. 178). Já as cores frias mostram o desinteresse gradativo no texto por parte dos leitores. Com esse parâmetro em mente, importa pontuar que os mapas de calor gerados pelos eye trackers demonstram que os participantes do Grupo I foram perdendo o interesse no texto a partir da segunda metade da página 1 . Isto só se altera nos primeiros parágrafos da página 3 (Figura 4).

Figura 4 - Mapas de calor: padrão de leitura do Grupo I
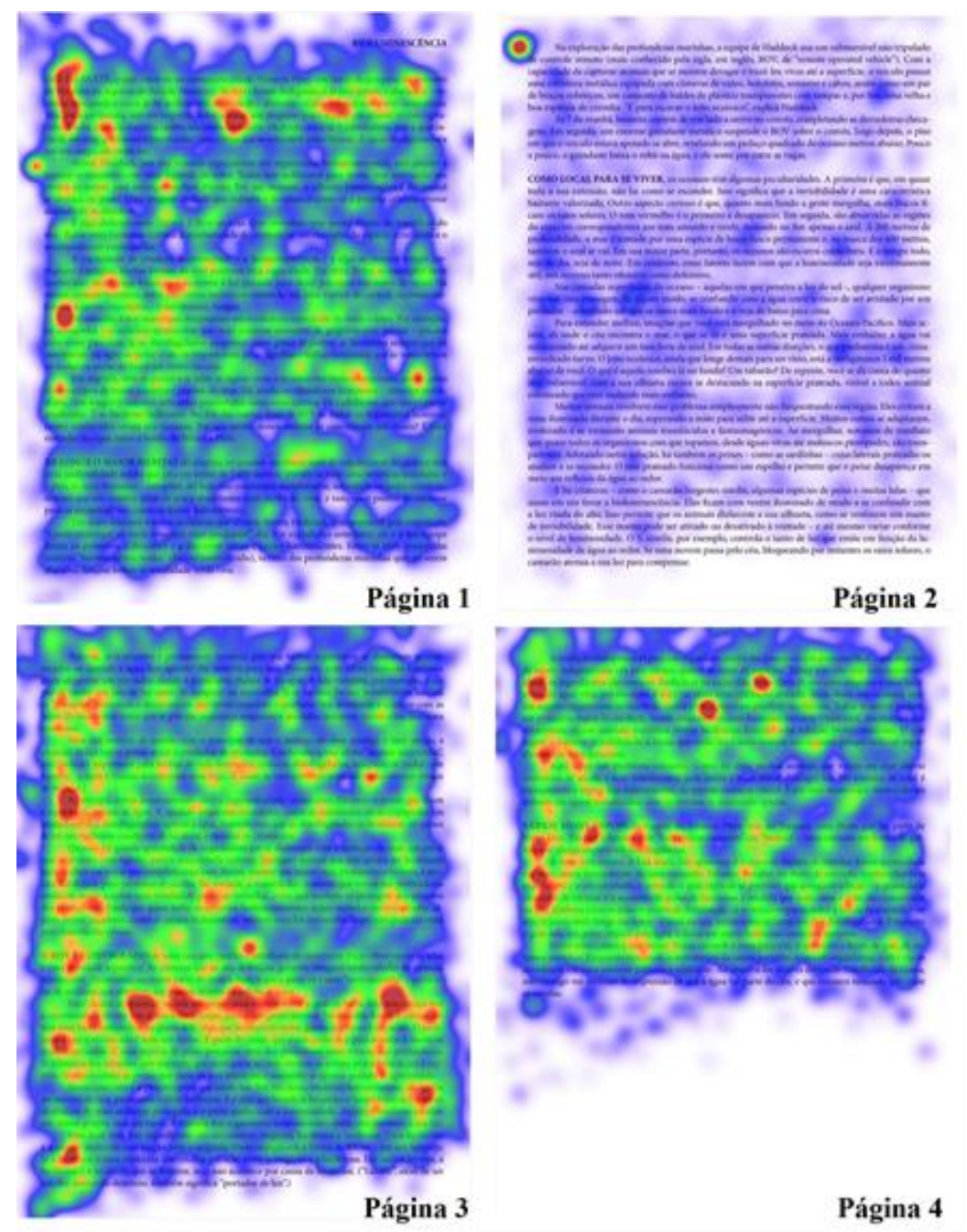

Fonte: Dados da pesquisa, a partir de métricas coletadas pelo eye tracker. 


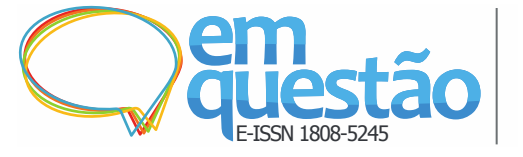

Já o Grupo II, que recebeu a reportagem completa, manteve interesse semelhante em todas as páginas, como podemos ver na figura 5.

Figura 5 - Mapas de calor: padrão de leitura do Grupo II
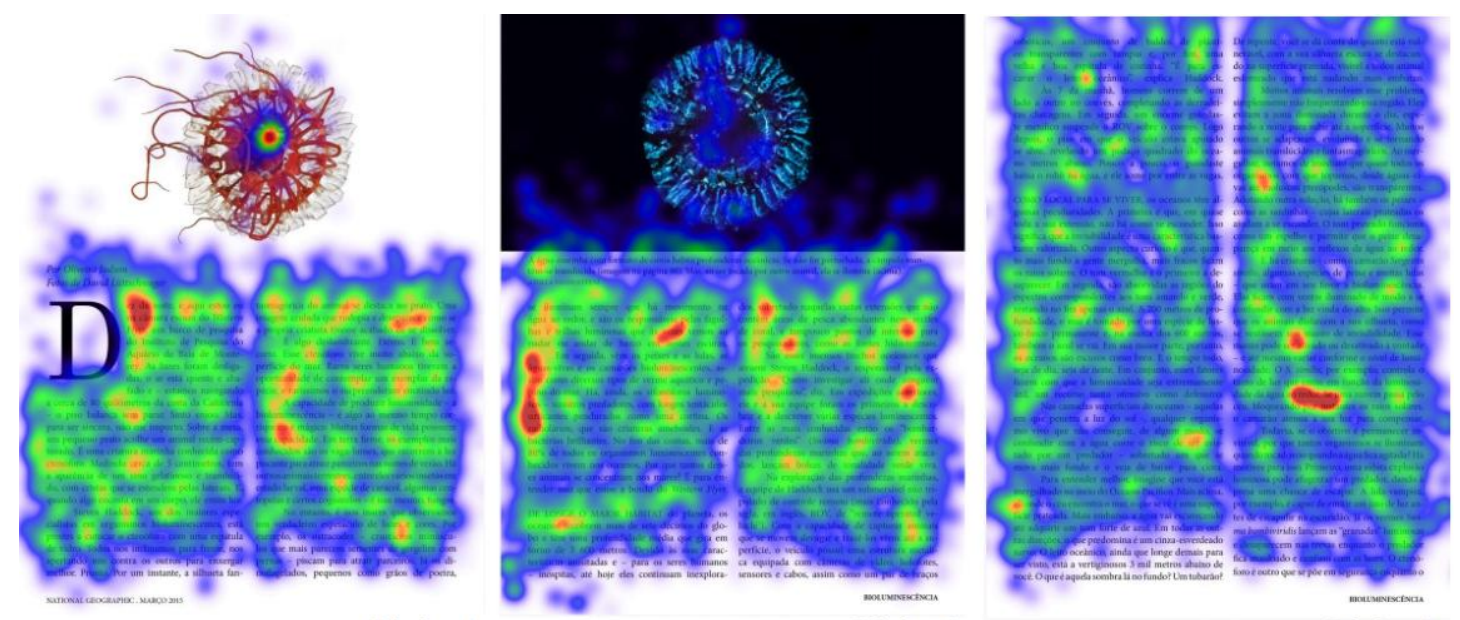

Página 1

Página 2

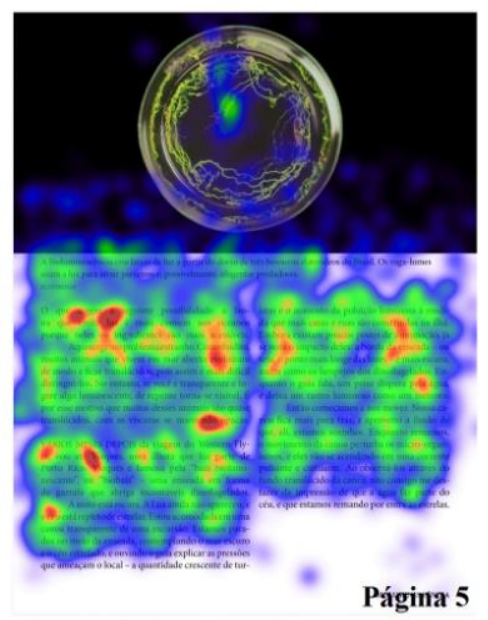

Página 4

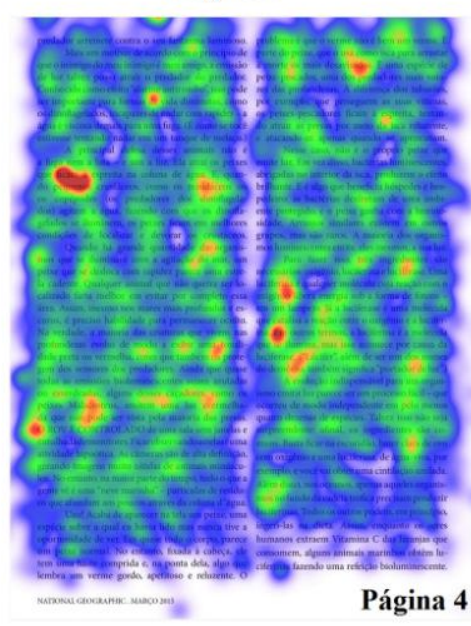

Página 3

Fonte: Dados da pesquisa, a partir de métricas coletadas pelo eye tracker.

\section{Considerações finais}

A pesquisa sinaliza que textos e imagens não concorrem entre si, ao contrário, eles encontram um no outro as complementariedades de que precisam. Imagens criam textos, que, por sua vez, criam imagens. Sinaliza, ainda, que fotografias têm amplo potencial para estimular a leitura dos textos, ajudar na compreensão e fornecer informações que vão além do que está escrito. 
No entanto, conforme já nos alertou Dubois (2009, p. 52) e, de certa forma, foi confirmado pela nossa pesquisa, "as fotografias propriamente ditas quase não têm significação nelas mesmas: seu sentido lhes é exterior, é essencialmente determinado por sua relação efetiva com o seu objeto e com sua situação de enunciação". Essa situação de enunciação é dada, parcialmente, pelo texto. Diante disso, podemos admitir o uso de fotografias em textos científicos como boa estratégia para contribuir com o discurso dos pesquisadores e jornalistas científicos e, consequentemente, para diminuir o distanciamento entre o público leigo e a ciência.

Junto a essa proposição, assumimos também que é imprescindível dispensar atenção especial na elaboração dessas imagens. É preciso atentar-se para uma produção que contemple a linguagem estruturante, hierárquica e sequencial do método científico (essencial no âmbito da pesquisa), tanto quanto os critérios técnicos de composição, profundidade de campo, granulação, perspectiva luz e sombra (fundamentais para sua apreciação estética). Melhor ainda, seria que, além de pesquisadores e jornalistas, a divulgação científica contasse efetivamente com o olhar atento e treinado de fotógrafos.

Outra preocupação a ser considerada é com a habilidade do público para decodificar, compreender e interpretar tais imagens - afinal, como acontece em outras linguagens, o leitor também precisa dispor de referências prévias. Por essa razão, não defendemos o uso da fotografia pela fotografia. Nem a supremacia das imagens em relação ao texto. Defendemos sim, a articulação dessas duas plataformas de comunicação como caminho privilegiado na busca pelo entendimento da ciência e consequente formação do conhecimento.

Certamente, restam ainda outros problemas a serem levantados, mesmo porque a fotografia não é a grande solucionadora para todos os males enfrentados por jornalistas e cientistas na divulgação da ciência. Mas, ela é, sem dúvida, valiosa ferramenta de comunicação. E, quando associada ao texto científico, torna-se capaz de despertar o interesse do público e facilitar a compreensão da ciência. 


\section{Agradecimentos}

Agradecemos aos pesquisadores colaboradores, Amilton Rogério Santos de Araújo, Yuri Manzi Giani, Bruno André Von Hauer, por toda a ajuda no planejamento e execução dos experimentos em laboratório; à fotógrafa, Rhanna Asevedo, pelos registros feitos durante todas as atividades da pesquisa; ao Centro Integrado de Aprendizagem em Rede (CIAR) da Universidade Federal de Goiás (UFG), na pessoa do então diretor, professor Leonardo Barra, pelo espaço concedido para a coleta de dados.

\section{Referências}

AUMONT, J. A imagem. Campinas: Papiros, 1993.

BARRETO, A. M. Eye tracking como método de investigação aplicado às ciências da comunicação. Revista Comunicando, [S.1.], v. 1, n. 1, p. 168-186, dez. 2012.

BARTHES, R. O óbvio e o obtuso: ensaios críticos III. Rio de Janeiro: Nova Fronteira, 1990.

BARTHES, R. A câmara clara. Rio de Janeiro: Nova Fronteira, 2012.

BRASIL. Conselho Nacional de Desenvolvimento Científico e Tecnológico. V Prêmio Fotografia: Ciência \& Arte 2015, 2015. Disponível em:

<http://www.premiofotografia.cnpq.br/web/pfca>. Acesso em: 30 set. 2015.

BRASIL. Ministério da Ciência, Tecnologia e Inovação. Centro de gestão e estudos estratégicos. Percepção pública da C\&T no Brasil 2015. 2015.

CORREIA, F. A ilustração científica: "santuário" onde a arte e a ciência comungam. Visualidades, Goiânia, v. 9, n. 2, p. 221-239, jun./dez. 2011.

DUBOIS, P. O ato fotográfico e outros ensaios. Campinas: Papiros, 2009.

FABRIS, A.; KERN, M. B. Imagem e conhecimento. São Paulo: Edusp, 2006.

FLUSSER, V. Filosofia da caixa preta: ensaios para uma futura filosofia da fotografia. Rio de Janeiro: Relume Dumará, 2002.

FUJIYOSH, S.; COSTA, M. C. Indicadores de percepção pública da ciência e da tecnologia no Brasil: estudo comparativo sobre a cobertura da imprensa. Campinas, 2003. 
GRUSZYNSKI, A. C.; CASTEDO, R. Comunicação científica e cultura visual: desafios para a publicação de periódicos on-line. Lumina: revista do Programa de Pós-Graduação em Comunicação, Juiz de Fora, v. 2, n. 2, p. 1-15, dez. 2008. Disponível em: <http://lumina.ufjf.emnuvens.com.br/lumina/article/view/167>. Acesso em: 22 jun. 2016.

HERNANDO, C. Divulgação científica: um grande desafio para este século. Entrevistadores: L. Massarani e I. C. Moreira. São Paulo: Ciência e Cultura, 2005.

MACHADO, A. O quarto iconoclasmo e outros ensaios hereges. Rio de Janeiro: Rios Ambiciosos, 2001.

MANGUEL, A. O espectador comum: a imagem como narrativa. In: MANGUEL, A. Lendo imagens: uma história de amor e ódio. São Paulo: Companhia das Letras, 2001.

MORA, A. M. S. A divulgação da ciência como literatura. Rio de Janeiro: Editora UFRJ, 2003.

OLIVEIRA, F. de. Jornalismo científico. São Paulo: Contexto, 2002.

ORGANIZAÇÃO DAS NAÇÕES UNIDAS. Declaração universal dos Direitos Humanos. Rio de Janeiro: UNIC Rio, 2009.

PERNICE, K.; NIELSEN, J. How to conduct eyetracking studies. [S.1.]: Nielsen Norman Group, 2009.

ROUILLÉ, A. A fotografia: entre documento e arte contemporânea. Tradução: Constancia Egrejas. 3. ed. São Paulo: SENAC, 2009.

SAMAIN, E. Aula inaugural. 1 vídeo online (134 min). Transmissão ao vivo da aula inaugural do Programa de Pós-Graduação em Arte e Cultura Visual da Universidade Federal de Goiás, realizada em 2 mar. 2015. Disponível em: <https://youtu.be/8aZ5exbj3Pk>. Acesso em: 2 maio 2016.

SAMAIN, E. As imagens não são bolas de sinuca. In: SAMAIN, E. (Org.). Como pensam as imagens. Campinas: Unicamp, 2012. p. 21-36.

SILVA, A. L. et al. A fotografia no Jornalismo Científico: a divulgação da ciência e tecnologia na mídia impressa Sergipana Cinform e Jornal da Cidade. Revista Anagramas: revista científica interdisciplinar de graduação, São Paulo, v. 6 , n. 1 , p. $1-15$, set./nov. 2012

SCHILLING, G.; CHRISTENSEN, L. L. Eyes on the skies: 400 years of telescopic discovery. IAU: ESA-Hubble/ESO, 2009. 
TUNDISI, José Galízia. Apresentação. In: MAYOR, Frederico; FORTI, Augusto. Ciência e poder. Campinas: Papirus: Brasília: Unesco, 1998, p. 7-9.

\title{
Eyetracking analysis of the use of photography in scientific dissemination
}

\begin{abstract}
This paper investigates photography as an enabling tool in the process of understanding scientific knowledge by the general public. Our hypothesis is that scientific texts, associated with photography, have major possibility to spark the interest of general public and facilitate the understanding of the information. It is based on Flusser's theory that images such as photography provide less abstract thoughts than texts; in Samain's papers that classify photography as a valuable way to communicate; and other scholars theories such as Correia, Gruszynski and Castedo, Machado and Mora - who believe that speech and writing no longer need to be the only forms of scientific communication. The research is characterized as exploratory, with experimental - laboratory design and it adopts qualitative and quantitative approaches. The results show different patterns of reading, degree of attention and understanding of the scientific text, when subjects are presented to different text structures. The results show different patterns of reading, as much as different levels of attention and understanding, when the subjects were presented to diverse text structures (text with photos, text by itself and photos by themselves). The text with photos was better understood and considered easy to read, followed by the text by itself. The least understood material was the one that presented only photos. Participants who read texts considered that photos helped reading and apprehending its content. The group that read only photos missed the text. It is considered that the research hypothesis was confirmed.
\end{abstract}

Key words: Popularization of science. Eye tracker. Photography.

Recebido: 01/05/2017

Aceito: 03/10/2017

\footnotetext{
${ }^{1}$ Dentre os pesquisadores destacamos José Reis, Roberto Lent, Antonio Carlos Pavão, Leopoldo de Méis, Vanderlei Bagnato, Suzana Herculano e Leila Maria Beltramini.
} 